\section{THU0525 SAFETY OF ADALIMUMAB \pm METHOTREXATE FOR THE TREATMENT OF POLYARTICULAR JUVENILE IDIOPATHIC ARTHRITIS (PJIA): STRIVE REGISTRY}

N. Ruperto ${ }^{1}$, H. Brunner ${ }^{2}$, K. Nanda ${ }^{2}$, M. Toth ${ }^{2}$, I. Foeldvari ${ }^{1}$, J. Bohnsack ${ }^{2}$, D. Milojevic ${ }^{2}$, C. Rabinovich ${ }^{2}$, D. Kingsbury ${ }^{2}$, K. Marzan ${ }^{2}$, P. Quartier ${ }^{1}$,

K. Minden ${ }^{1}$, E. Chalom ${ }^{2}$, G. Horneff ${ }^{1}$, R. Kuester ${ }^{1}$, J. Dare ${ }^{2}$, M. Bereswill ${ }^{3}$, J. Kalabic ${ }^{3}$, H. Kupper ${ }^{3}$, A. Martini ${ }^{1}$, D. Lovell ${ }^{2} .{ }^{1}$ PRINTO-IRCCS Gaslini, Genova, Italy; ${ }^{2} P R C S G$, Cincinnati Children's Hospital Medical Center, Cincinnati, United States; ${ }^{3} \mathrm{AbbVie}$ Deutschland GmbH \& Co. KG, Ludwigshafen, Germany

Background: JIA is the most common chronic inflammatory rheumatic disease of childhood. TNF inhibitors are used for long-term control of pJIA disease.

Objectives: To evaluate the 7 year (y) safety of Adalimumab treatment with or without methotrexate (ADA $\pm M T X)$ when used in current clinical practice for treatment of patients (pts) with active pJIA.

Methods: This is a 7 y interim analysis of an ongoing, multicenter, noninterventional, observational registry of pts with pJIA with up to10 y safety follow-up. Included pts were treated with $\mathrm{ADA} \pm \mathrm{MTX}$ or MTX alone as comparison arm according to routine clinical care in PRINTO/PRCSG centres in EU, USA and Australia. MedDRA observational adverse events (AEs) were recorded from 1st day in the registry through last contact, irrespective of duration of registry treatment.

Results: In January 2014, enrollment was complete. As of June 1, 2016 cut-off date, 838 pts (301- MTX arm and $537-A D A \pm M T X$ arm) were treated in the registry. There were 39 pts who rolled over from MTX to ADA $\pm M T X$ arm. At registry entry mean pJIA disease duration was $1.3 \mathrm{y}$ and $3.7 \mathrm{y}$ and mean AJC71 was 5.8 and 5.2 for MTX and ADA \pm MTX arms, respectively. CHAQ disability index was 0.6 for both arms. Mean duration of study drug exposure in registry was 2.0 y (range: $0.0-7.1$ ) and 2.5 y (range: $0.0-7.9$ ) for MTX and ADA \pm MTX arms, respectively. Mean duration of observation in registry was 3.9 y (range: 0.0 - 7.2) and 3.5 y (range: $0.0-7.9$ ) for MTX and ADA \pm MTX arms, respectively. Overall, 213 pts $(70.8 \%)$ in MTX and 225 pts $(41.9 \%)$ in ADA \pm MTX arms discontinued registry drug through $7 \mathrm{y}$. Main reasons (not exclusively) for registry drug discontinuation for MTX arm: pts required additional therapy (32.6\%), other $(13.3 \%)$, lack of efficacy $(11.6 \%)$, AEs $(9.3 \%)$, or pts achieved JIA remission (8.6\%); for ADA \pm MTX arm: lack of efficacy $(17.9 \%)$, other (7.3\%), lost to follow-up $(5.6 \%)$, AEs $(5.4 \%)$, or pts achieved JIA remission (5.0\%). Frequencies and rates of treatment-emergent AEs (from 1st dose date of registry drug in registry up to last dose +70 days in registry, excluding AEs occurring during treatment interruption) were similar to those reported for observational AEs (from 1st day in registry up to last contact irrespective of drug treatment duration) (Table). Rate of serious infections was similar between MTX and ADA \pm MTX arms. One pt $(0.2 \%)$ reported an event of opportunistic infection (fungal oesophagitis) in ADA \pm MTX arm. No reports of deaths, malignancies, active tuberculosis, oral candidiasis, demyelination, or congestive heart failure.

\begin{tabular}{|c|c|c|c|c|c|c|}
\hline & \multicolumn{2}{|c|}{ MTX } & \multicolumn{4}{|c|}{ ADA $\pm M T X$} \\
\hline & \multirow[b]{2}{*}{$\begin{array}{l}\mathrm{N}=301 \\
\mathrm{n}(\%)\end{array}$} & \multirow[b]{2}{*}{$\begin{array}{c}P Y s=1170.3 \\
E(E / 100 \\
P Y s)\end{array}$} & \multicolumn{2}{|c|}{$A D A$ only } & \multicolumn{2}{|c|}{$A D A+M T X^{\prime \prime}$} \\
\hline & & & $\begin{array}{l}\mathrm{N}=160 \\
\mathrm{n}(\%)\end{array}$ & $\begin{array}{c}P Y_{s}=517.0 \\
E(E / 100 \\
\left.P Y_{s}\right)\end{array}$ & $\begin{array}{l}\mathrm{N}=377 \\
\mathrm{n}(\%)\end{array}$ & $\begin{array}{l}P Y s=1338.5 \\
E(E / 100 P Y s)\end{array}$ \\
\hline Any AE & $\begin{array}{l}157 \\
(52.2)\end{array}$ & $505(43.2)$ & $66(41.3)$ & $216(41.8)$ & $178(47.2)$ & $553(41.3)$ \\
\hline $\begin{array}{l}\text { AE at least "possibly } \\
\text { drug related" per the } \\
\text { investigator }\end{array}$ & $87(28.9)$ & $197(16.8)$ & $30(18.8)$ & $66(12.8)$ & $88(23.3)$ & $177(13.2)$ \\
\hline Severe AE & $17(5.6)$ & $23(2.0)$ & $14(8.8)$ & $22(4.3)$ & $25(6.6)$ & $41(3.1)$ \\
\hline Serious AE & $32(10.6)$ & $52(4.4)$ & $21(13.1)$ & $39(7.5)$ & $56(14.9)$ & $95(7.1)$ \\
\hline $\begin{array}{l}\text { AE leading to } \\
\text { discontinuation of } \\
\text { study drug or study }\end{array}$ & $28(9.3)$ & $36(3.1)$ & $13(8.1)$ & $19(3.7)$ & $25(6.6)$ & $40(3.0)$ \\
\hline Infectious AE & $87(28.9)$ & $179(15.3)$ & $38(23.8)$ & $75(14.5)$ & $105(27.9)$ & $187(14.0)$ \\
\hline Serious infectious AE & $14(4.7)$ & $17(1.5)$ & $6(3.8)$ & $8(1.5)$ & $22(5.8)$ & $30(2.2)$ \\
\hline $\begin{array}{l}\text { Injection site-related } \\
\mathrm{AE}\end{array}$ & $6(2.0)^{*}$ & $8(0.7)$ & $5(3.1)$ & $6(1.2)$ & $24(6.4)$ & $32(2.4)$ \\
\hline
\end{tabular}

$\mathrm{E}$, events; PYs, patient years (Observation time irrespectively of study drug treatment duration). ${ }^{*} 3$ patients experienced injection site-related AEs with etanercept injections. During the registry, $52(17.3 \%)$ pts in MTX arm and $45(8.4 \%)$ ptsin ADA arm started mith a biologic DMARD. $M T X$ was used at any point of time during the course of the registry.

Conclusions: Overall, ADA \pm MTX was well-tolerated in these pts with pJIA with no new safety signals. The retention rate for registry drug was higher in ADA \pm MTX arm compared to MTX arm

Acknowledgements: AbbVie sponsored the study \& contributed with PRINTO \& PRCSG to analysis, review, approval of the abstract. X. Leahy \& A. Deshmukh (AbbVie) contributed to research. Medical writing: G. Patki (AbbVie).

Disclosure of Interest: N. Ruperto Grant/research support from: AbbVie Inc. AstraZeneca, Bristol-Myers Squibb, Janssen Biologics B.V., Eli Lilly and Co., "Francesco Angelini", GlaxoSmithKline, Italfarmaco, Novartis, Pfizer, Roche, Sanofi Aventis, Schwarz Biosciences GmbH, Xoma, and Wyeth Pharmaceuticals, Employee of: GASLINI Hospital, Speakers bureau: Astellas, AstraZeneca, BristolMyers Squibb, Italfarmaco, Janssen Biologics B.V., Medlmmune, Roche, and Wyeth/Pfizer, H. Brunner Consultant for: AbbVie Inc., AstraZeneca, Centocor Bristol-Myers Squibb, Boehringer-Ingelheim, Pfizer, Regeneron, Hoffman LaRoche, Novartis, Takeda, UCB, and Genentech, Speakers bureau: Genentech Pharmaceuticals, K. Nanda Consultant for: Medac Pharma, Inc., M. Toth: None declared, I. Foeldvari Consultant for: AbbVie and Novartis, J. Bohnsack Consultant for: Novartis, D. Milojevic Consultant for: Genentech and Novartis, C. Rabinovich Grant/research support from: UCB Pharma, Janssen, D. Kingsbury: None declared, K. Marzan Grant/research support from: AbbVie, P. Quartie Grant/research support from: AbbVie, Novartis, Pfizer, BMS, Chugai-Roche, Medimmune, Servier, and Swedish Orphan Biovitrum, Consultant for: AbbVie, Novartis, Pfizer, BMS, Chugai-Roche, Medimmune, Servier, Swedish Orphan Biovitrum, and Sanofi, K. Minden Grant/research support from: Pfizer, AbbVie and Roche/Chugai, Consultant for: Pfizer, Roche, and Pharma-Allergan, Speakers bureau: Pfizer, Roche, and Pharma-Allergan, E. Chalom Speakers bureau: AbbVie, G. Horneff Grant/research support from: AbbVie, Pfizer, Novartis, and Roche, Speakers bureau: AbbVie, Novartis, Sobi, Pfizer, and Roche, R. Kuester Grant/research support from: AbbVie Inc. and Wyeth/Pfizer, J. Dare Grant/research support from: AbbVie, AstraZeneca, Bristol-Myers Squibb, Horizon Pharma, Medac, Pfizer, Roche, and UCB, M. Bereswill Shareholder of: AbbVie, Employee of: AbbVie, J. Kalabic Shareholder of: AbbVie, Employee of: AbbVie, H. Kupper Shareholder of: AbbVie, Employee of: AbbVie, A. Martini Grant/research support from: AbbVie Inc., AstraZeneca, Bristol-Myers Squibb, Janssen Biologics B.V., Eli Lilly and Co., "Francesco Angelini", GlaxoSmithKline, Italfarmaco, Novartis, Pfizer, Roche, Sanofi Aventis, Schwarz Biosciences GmbH, Xoma and Wyeth Pharmaceuticals, Employee of: GASLINI Hospital, Speakers bureau: Astellas, AstraZeneca, Bristol-Myers Squibb, Italfarmaco, and Medlmmune, D. Lovell Consultant for: AstraZeneca, Centocor, Bristol-Myers Squibb, Pfizer, Regeneron, Hoffman La-Roche, Novartis, UBC, Xoma, Genentech, Amgen and Forest Research, Speakers bureau: Wyeth Pharmaceuticals

DOI: 10.1136/annrheumdis-2017-eular.2010

\section{THU0526 SHORT AND LONG-TERM FOLLOW-UP OF TOCILIZUMAB FOR SEVERE JUVENILE IDIOPATHIC ARTHRITIS-ASSOCIATED UVEITIS}

N. Vegas-Revenga ${ }^{1}$, V. Calvo-Río ${ }^{1}$, M. Santos-Gómez ${ }^{2}$, I. Calvo ${ }^{3}$, M. González-Fernández ${ }^{3}$, B. López-Montesinos ${ }^{3}$, M. Mesquida ${ }^{4}$, A. Adan ${ }^{4}$

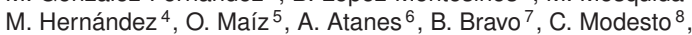

G. Díaz-Cordovés ${ }^{9}$, N. Palmou-Fontana ${ }^{1}$, J. Loricera ${ }^{1}$, M. González-Vela ${ }^{1}$ R. Demetrio-Pablo ${ }^{1}$, L. Domínguez-Casas ${ }^{1}$, C. Fernández-Díaz ${ }^{1}$

J. Hernández ${ }^{1}$, M. González-Gay ${ }^{1}$, R. Blanco ${ }^{1} .{ }^{1} H U M V$, Santander; ${ }^{2} H$, Torrelavega; ${ }^{3} \mathrm{H} \mathrm{Fe}$, Valencia; ${ }^{4} \mathrm{H}$ Clinic, Barcelona; ${ }^{5} \mathrm{H}$, Donostia; ${ }^{6} \mathrm{HUAC}, \mathrm{A}$ Coruña; ${ }^{7} \mathrm{H}$ Nieves, Granada; ${ }^{8} \mathrm{H}$ V d'Hebron, Barcelona; ${ }^{9} \mathrm{H}$, Málaga, Spain

Objectives: To assess the efficacy of tocilizumab (TCZ) at short and long term follow-up for severe juvenile idiopathic arthritis-associated uveitis.

Methods: Multicentre study of 25 patients who had inadequate response to traditional treatment with corticosteroids and at least one conventional immunosuppressive drug including biological therapy. The outcome variables were the degree of inflammation, visual acuity and macular thickness. The results are expressed as mean $\pm \mathrm{SD}$ for normally distributed variables, or median [IQR] when are not. Comparison of continuous variables was performed using the Wilcoxon test.

Results: We studied 25 patients (21 women/4 men); mean age 18.6 \pm 8.3 . Uveitis was bilateral in 22. JIA subsets were oligoarthritis $(n=17)$, polyarthritis (5), psoriatic (2) and enthesitis-related arthritis (1). Ocular sequelae at TCZ onset were cataracts (13), glaucoma (7), synechiae (10), band keratopathy (12), maculopathy (9), and amblyopia (5). Pattern of uveitis was: anterior (17), panuveitis (4), intermediate (2) and posterior (2). Before TCZ, they had received corticosteroids, conventional immunosuppressive drugs and biologics, including adalimumab (24), etanercept (8), infliximab (7), abatacept (6), rituximab (2), anakinra (1), and golimumab (1). TCZ dosage regimen was $8 \mathrm{mg} / \mathrm{kg} \mathrm{IV/4}$ weeks (21), every 2 weeks (2), every 8 weeks (1), or $2.9 \mathrm{mg} / \mathrm{kg} \mathrm{sc}$ every week (1). All outcome variables showed a rapid and maintained improvement (Table 1) after

Abstract THU0526 - Table 1

\begin{tabular}{|c|c|c|c|c|c|c|c|c|c|}
\hline & Baseline & 1st week & 2nd week & 1st month & 3rd month & 6th month & 1st year & 2nd year & 3rd year \\
\hline Visual acuity mea $\pm S D$ & $0.57 \pm 0.35$ & $0.55 \pm 0.35$ & $0.56 \pm 0.35$ & $0.59 \pm 0.33$ & $0.6 \pm 0.32^{*}$ & $0.63 \pm 0.32^{*}$ & $0.63 \pm 0.35^{\star}$ & $0.59 \pm 0.32^{*}$ & $0.45 \pm 0.34^{*}$ \\
\hline Anterior chamber cells median [IQR] & $1[0-1]$ & $0.75[0-1]^{*}$ & $0.5[0-1]^{*}$ & $0[0-0.5]^{*}$ & $0[0-0]^{*}$ & $0[0-0]^{\star}$ & $0[0-0]^{\star}$ & $0[0-0]^{\star}$ & $0[0-0]^{*}$ \\
\hline Vitritis median [IQR] & $0[0-0]$ & $0[0-1]$ & $0[0-0]$ & $0[0-0]$ & $0[0-0]^{*}$ & $0[0-0]^{\star}$ & $0[0-0]^{*}$ & $0[0-0]^{*}$ & $0[0-0]$ \\
\hline OCT (microns) mean \pm SD & $358.69 \pm 92.17$ & $351.4 \pm 108.29$ & $336.5 \pm 100.9^{*}$ & $313.4 \pm 91.28^{*}$ & $280.7 \pm 35.03^{\star}$ & $274.9 \pm 101.33^{\star}$ & $245.4 \pm 29.4^{*}$ & $239.6 \pm 33.5$ & ND \\
\hline
\end{tabular}

${ }^{*} \mathrm{p}<0.05$ compared with basal. 
a follow up of one year $(n=21), 2$ years $(n=11)$, and 3 years $(n=5)$. A reduction in the daily median dose of prednisone from $10 \mathrm{mg}[0-15 \mathrm{mg}]$ to $0[0-0 \mathrm{mg}] \mathrm{in}$ 3 years, $(p<0.05)$ was observed. After a median follow-up of $20.5 \pm 11.7$ months in 4 patients, the interval between TCZ doses was increased to 5 weeks $(n=2)$, 6 weeks (1) and 7 weeks (1) because of remission. TCZ had to be withdrawn due to articular inefficiency (1) or articular and ocular inefficiency (1). The main adverse effects were severe autoimmune thrombocytopenia, autoimmune anemia and thrombocytopenia, pneumonia, viral conjunctivitis and bullous impetigo in 1 patient each.

Conclusions: TCZ is useful at short and long term follow-up for severe Juvenile Idiopathic Arthritis-associated uveitis. It is possible to optimize the TCZ dose.

Disclosure of Interest: None declared

DOI: 10.1136/annrheumdis-2017-eular.5265

\section{THU0527 PEDIATRICIAN AND ADULT RHEUMATOLOGIST COLLABORATING IN A MULTIDISCIPLINARY REUMA-PED CLINIC. IS THIS TRANSITIONAL CARE MODEL EFFECTIVE?}

P. Collado ${ }^{1}$, A. Rubio ${ }^{1}$, R. Diaz-Delgado ${ }^{2}$, C. Calvo ${ }^{2}$, R. Mustienes ${ }^{1}$, F. Rey $^{1}$ C. Bonilla ${ }^{1}$, E. Cruz ${ }^{1}$. ${ }^{1}$ Rheumatology; ${ }^{2}$ Pediatric, Hospital Universitario Severo Ochoa, Madrid, Spain

Background: Transitional care should be a planned movement of adolescents with chronic diseases from child-centred to adult-oriented health care system. Recently a EULAR/PReS taskforce has developed the first international set of recommendations and standards for transitional care ${ }^{1}$

Objectives: To describe the results from a specific transitional care programme. Methods: The current transitional care programme includes a multidisciplinary PED-REUMA clinic (MPRC) weekly and a non-defined period of rheumatologic follow-ups by the same rheumatologist of MPRC. The transitional care team is composed of two pediatricians, one adult rheumatologist -as transition coordinator, a clinical nurse specialist and administrative support, as well as a psychologist and physiotherapists. Clinical information and therapies were collected throughout the disease course, and the HEADSS method of psychosocial interviewing has been included recently.

Population of the present study included young patients (YP) from that programme who are going to transfer to adult-oriented health care system. Descriptive study of socio-demographics and clinic features was included, as well as patients' adherence. YP confidence to be transferred and satisfaction with the current transitional process were measured using on a scale of 0 to 10 . In patients suffering from juvenile idiopathic arthritis (JIA), clinical status of disease activity and clinical remission and $\mathrm{CHAQ}$ were tested before transfer.

Results: Twenty-seven YP with female predominance (63\%) were included. The average age was $21 \pm 3$ yo at time of a planned transfer and $16 \pm 3.4$ yo at inclusion to the MPRC. JIA was the commonest condition whereas dermatomyositis was uncommon. Up to $63 \%$ patients required some DMARDs during the MPRC follow-up, but only a 37\% needs maintained immunosuppressive therapies and three $(11 \%)$ patients required changing the therapeutic target before transfer. YP adherence to rheumatologist appointments was high. Regarding HEADSS data: most YP were students and living at family home, around $50 \%$ gave up sports or other activities due to homework or exams, $29 \%$ of YP occasionally drank some alcohol but none used tobacco, and $47 \%$ of YP felt sad or down once in a while. Patient's confidence to be transferred was $7.7 \pm 2.1$ (mean $\pm S D$; min-max: $2-10)$. YP showed high satisfaction with the current transitional process, $9.7 \pm 0.4$ (min-max: 9-10)

Before transfer, 17 patients with JIA showed a mean \pm SD value of JADAS10 of $2 \pm 5$ (min-max, $0-18$ ), clinical remission on/off medication was $23 \%$ and $53 \%$ respectively. Mostly functional status reported by patient was low, YP-rated CHAQ (mean 0.06; min-max, 0.0-0.75).

Conclusions: To the best of our knowledge, this is the first study evaluating a Spanish transitional care programme. The study reports a positive impact across adolescence of our transitional care model in a real life situation. Implementation of recommendations depended on the local available resources.

[1] Foster HE. EULAR/PReS standards and recommendations for the transitional care of young people with juvenile-onset rheumatic diseases. Ann Rheum Dis Published Online First: [1, November 2016] doi:10.1136/ annrheumdis-2016210112.

Acknowledgements: Beatriz Jimenez. Auxiliary to the clinical nurse specialist and administrative support of Rheumatology Department.

Disclosure of Interest: None declared

DOI: 10.1136/annrheumdis-2017-eular.5444

\section{THU0528 STING-ASSOCIATED VASCULOPATHY WITH ONSET IN INFANCY (SAVI): A DIFFERENTIAL DIAGNOSIS OF INFLAMMATORY INTERSTITIAL LUNG DISEASE}

$\underline{\text { R. Dagher }}{ }^{1}$, R. Ghiye ${ }^{1}$, G. Nicolas ${ }^{1}$, H. Feghali ${ }^{1}$, M.C. Fadous Khalife ${ }^{1}$, L. Seabra ${ }^{2}$, Y.J. Crow ${ }^{2}$. 1 Pediatrics, Notre Dame de Secours University Hospital, Byblos, Lebanon; ${ }^{2}$ Paris-Descartes University, Sorbonne-Paris-Cite, Institut Imagine, INSERM UMR 1163, Paris, France

Background: STING-Associated Vasculopathy with onset in Infancy (SAVI) is an auto-inflammatory monogenic disease. SAVI is caused by an upregulation of type I interferon signaling due to sporadic or inherited gain-of-function mutations in the STimulator of INterferon Gene (STING)/Transmembrane Protein 173 (TMEM173) The first description of this phenotype, and the identification of the mutated gene was in 2014. SAVI is characterized mainly by cutaneous vasculopathy leading to necrotic lesions, and progressive interstitial lung disease with secondary fibrosis. Objectives: SAVI is a rare disease with unknown prevalence. To the best of our knowledge, 25 cases have been reported so-far. These patients variably manifest cutaneous lesions and inflammatory lung disease. Here we present a case of SAVI with onset of features at the age of 3 years.

Methods: A now 8 year old boy born to non-consanguineous parents was described to have experienced recurrent fevers, polyarthralgia and polyarthritis, livedo of the limbs, facial telangiectasia, necrotic lesions of auricles and digits and failure to thrive since the age of 3 years. He has normal cognitive development. His familial history is notable for epilepsy in 2 of his siblings and Behcet disease in a paternal cousin.

Laboratory tests at age 6.5 years revealed increased ESR $(60 \mathrm{~mm} / \mathrm{h})$ while CRP varied from 3 to $14 \mathrm{mg} / \mathrm{L}$. ANA titres were positive (1/640), with normal complement level and negative anti-DNA. c-ANCA and p-ANCA were negative. $\mathrm{ECA}$ and lysozymes were in the normal range. Although the child had no respiratory symptoms, chest $\mathrm{X}$-ray revealed diffuse interstitial parenchymal infiltrates. Chest angio-CT showed ground-glass lesions with fibrotic bands and mediastinal and para-hilar adenopathies. FVC and DLCO were reduced on pulmonary functional testing. Lung biopsy was not performed.

Empirical treatment with pulse and oral corticosteroids along with azathioprine was started. Over a period of one year, systemic inflammation and skin involvement regressed dramatically, but his lung disease showed no improvement.

Results: Genetic testing identified a previously reported V155M mutation in TMEM173.

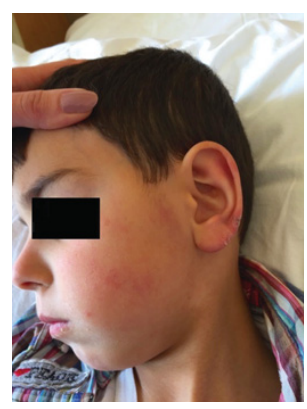

Conclusions: SAVI is associated with significant morbidity and mortality. The diagnosis should be considered in children with interstitial lung disease after more common causes have been ruled out. Steroids and immunosuppressive therapies apparently show no efficacy in avoiding progression to irreversible lung damage. Promising results with treatment by Janus Kinase inhibitors as a means of blocking signaling downstream of the type I interferon receptor were recently published.

References:

[1] Y. Liu, A.A. Jesus, B. Marrero, et al. Activated STING in a vascular and pulmonary syndrome. N Engl J Med, 371 (2014), pp. 507-518.

[2] N. Jeremiah, B. Neven, M. Gentili, et al. Inherited STING-activating mutation underlies a familial inflammatory syndrome with lupus-like manifestations. J Clin Invest, 124 (2014), pp. 5516-5520.

[3] Fremond ML, Rodero MP, et al. Efficacy of the Janus Kinase 1/2 inhibitor ruxolitinib in the treatment of vasculopathy associated with TMEM173activating mutations in 3 children. J Allergy Clin Immunol. 2016 Dec; 138(6): 1752-1755.

Acknowledgements: We thank Isabelle Melki for her valuable assistance in this case.

Disclosure of Interest: None declared

DOI: 10.1136/annrheumdis-2017-eular.4489

\section{THU0529 METHOTREXATE TREATMENT RESPONSE IN NON-SYSTEMIC JUVENILE IDIOPATHIC ARTHRITIS}

R. Bakry, G. Horneff. Asklepios, Sankt Augustin, Germany

Background: Methotrexate is approved and recommend as first line disease modifying antirheumatic drug (DMARD) in polyarticular juvenile idiopathic arthritis (JIA). In can be used orally or via s.c. injection.

Objectives: S.c MTX is thought to be more efficious or act more rapidly than oral MTX. Thus we want to analyse the kinetic of response in JIA patients treated with oral versus s.c. MTX.

Methods: In the German BIKER registry a cohort of biologics naïve JIA patients starting treatment with MTX was built. The data bank was screened for patients treated with MTX orally vs. s.c for the first time. The JIA-ACR 90 and the JADAS10 definition of remission were used as outcome parameters.

Results: $410 \mathrm{JIA}$ patients received treatment with oral MTX and 384 received s.c. MTX. RF negative polyarthritis was the most common JIA category $(50 \% / 51 \%)$ 